\title{
Validation of a Commercial System for Remote Estimation of Wetness Duration
}

\author{
Mark L. Gleason and Sharon K. Parker, Department of Plant Pathology, Iowa State University, Ames; Ron E. \\ Pitblado, Ridgetown College, Ridgetown, Ontario, Canada; Richard X. Latin, Department of Botany and Plant \\ Pathology, Purdue University, West Lafayette, IN; Donna Speranzini, Ontario Ministry of Agriculture, Food, and \\ Rural Affairs, Ridgetown, Ontario, Canada; Ruth V. Hazzard, Entomology Department, University of Massachu- \\ setts, Amherst; Martha J. Maletta and Winfred P. Cowgill, Jr., Rutgers Cooperative Extension, Flemington, NJ; \\ and Darvin L. Biederstedt, Campbell Soup Company, Napoleon, OH
}

\begin{abstract}
Gleason, M. L., Parker, S. K., Pitblado, R. E., Latin, R. X., Speranzini, D., Hazzard, R. V., Maletta, M. J., Cowgill, W. P., Jr., and Biederstedt, D. L. 1997. Validation of a commercial system for remote estimation of wetness duration. Plant Dis. 81:825-829.

To assess the accuracy of remote, real-time mathematical simulations of wetness duration and air temperature, hourly measurements of wetness duration and air temperature at 18 sites in the United States and Canada from May to September 1995 were compared with simulations for these sites provided by SkyBit, Inc. SkyBit simulations of mean, maximum, and minimum daily air temperatures varied from on-site measurements by less than $0.7^{\circ} \mathrm{C}$ but underestimated the duration of wet periods by an average of $3.4 \mathrm{~h} /$ day. At five of six stations tested, SkyBit underestimates of wetness duration were significantly $(P<0.01)$ larger on days when no rain was measured than on rainy days, indicating that simulations of dew-period duration were much less accurate than simulations of rain-period duration. The vast majority of hours SkyBit misclassified as dry occurred either when entire wet periods were missed $(59.3 \%)$ or when the onset of a wet period was detected late $(28.4 \%)$. The results suggest that revision of SkyBit wetnesssimulation models should focus on reducing error rates during dew events. In simulations using two disease-warning models, TOM-CAST and Melcast, with mean values of measured and SkyBit-simulated wetness duration, SkyBit-simulated values resulted in fewer and later fungicide spray advisories than did measured values. The magnitude of these impacts varied with the magnitude of the simulation errors and with differences in the models' decision rules.
\end{abstract}

Disease-warning systems are management tools that help growers assess the risk of crop damage from disease and thereby time the deployment of control tactics as efficiently as possible. The duration of periods of crop wetness, and air temperature during these wet periods, are key inputs for disease-warning systems because many fungal and bacterial pathogens are active only when free water is present and temperatures are conducive to their activity. Relatively few growers use disease-warning systems, however, despite convincing evidence that they can reduce pesticide use substantially compared with traditional, calendar-based spray schedules with no added risk of yield loss $(1,2,4)$. The expense and inconvenience of measuring weather inputs, especially wetness duration, is a critical barrier to wider implementation of disease-warning systems $(1,4,7)$.

Corresponding author: Mark L. Gleason

E-mail: mgleason@iastate.edu

Accepted for publication 4 April 1997.

Publication no. D-1997-0424-09S

(C) 1997 The American Phytopathological Society
To circumvent the need to measure wetness duration, attempts have been made to estimate it with empirical and/or quantitative models based on values of other weather parameters such as rainfall, relative humidity, wind speed, air temperature, and radiation $(5,7,11)$. However, all of these models have significant practical limitations for growers, often due to unavailability of the inputs in the vicinity of individual farms.

The advent of commercial services that deliver site-specific, real-time estimates of wetness duration should make diseasewarning systems much easier to use. SkyBit, Inc. (Boalsburg, PA), through its "EWeather" service, is the first commercial firm to offer site-specific, simulated observations and forecasts (14). These simulations, which utilize measurements at weather stations throughout the United States and Canada, mesoscale meteorological models, and Geographic Information Systems programs, are delivered to end users by electronic mail or fax. By freeing growers from the burden of obtaining their own weather inputs, such services have the potential to accelerate implementation of disease-warning systems (1). The accuracy of these wetness simulations requires thorough validation in field studies before they can be recommended for grower use. While electronic simulations of temperature and relative humidity have been evaluated as inputs to the Penn State Apple Orchard Consultant expert system (16) and a grape black rot expert system (18) at a single site, evaluations of simulated wetness duration as an input for disease-warning systems over multiple sites and geographic regions have not been published. The purposes of the present study were (i) to validate SkyBit estimates of wetness duration and air temperature against on-site measurements over a broad range of eastern North America; (ii) to assess the impact of wetness-estimation errors on timing of fungicide spray advisories by TOM-CAST and Melcast, disease-warning systems for tomatoes and melons, respectively; and (iii) to demonstrate an approach for validating wetnessestimation techniques as inputs to diseasewarning systems.

\section{MATERIALS AND METHODS}

On-site measurements. Hourly measurements of wetness and air temperature were made from May to September 1995 at 18 sites in the United States and Canada (Fig. 1). Sensors were located at unobstructed sites on managed turfgrass, on bare ground, or near the top of the canopy in melon or tomato fields. Wetness was measured as changes in electrical resistance, either of flat, printed-circuit sensors (Campbell Scientific, Logan, UT; Omnidata International, Inc., Logan, UT; Rainwise, Inc., Bar Harbor, ME; Sensor Instruments, Inc., Concord, NH) or, in Ontario only, of acrylic cylinders on which electrode wires were wound in shallow grooves cut as parallel spirals (15). Sensor surfaces were either painted with latex paint (3) (MA, IA, OH, Ontario) and ovendried before deployment or left unpainted (NJ, IN); in Indiana, sensor faces were covered with 1-mm-mesh, nylon window screen. Wetness sensors were deployed at heights of 15 to $45 \mathrm{~cm}$ above the ground, except at Snyder Farm, NJ, where sensor height increased from 30 to $100 \mathrm{~cm}$, corresponding to changes in height of the top of 
the tomato canopy over the course of the growing season. Flat wetness sensors were faced north at an angle of $45^{\circ}$ to horizontal, except in Indiana and Ohio, where sensors were deployed horizontally. Wetness sensors were calibrated before use to identify resistance thresholds associated with the transition between wet and dry environmental conditions. Electronic temperature sensors were thermistors deployed at heights of 20 to $135 \mathrm{~cm}$ and shaded from direct sunlight. Sensor readings were recorded by dataloggers at intervals of 1 to 6 min and summarized hourly. Rainfall was measured hourly or daily at six sites.

SkyBit data generation. SkyBit processes data from the U.S. National Weather Service (NWS) and Environment Canada using computer programs based on a weather model called MASS (Mesoscale Atmospheric Simulation System), which was developed for research in remote sensing applications by Kaplan et al. (8). The MASS model simulates finer scale, near-surface weather data than NWS models and provides detailed representation of mesoscale phenomena such as surface energy and water budgets; turbulent processes in the planetary boundary layer; deep moisture convection; atmospheric condensation, evaporation, and precipitation; and long- and short-wave radiation under clear and cloudy sky conditions. SkyBit combines the MASS model with high resolution and topological interpolation techniques developed by Kelley et al. (9). The SkyBit products we chose to test were hourly observations of mean air temperature and wetness $(0=$ dry, 1 = wet) for each location during the previous $24 \mathrm{~h}$. SkyBit simulations were delivered daily to fee-paying end users by electronic mail or fax.

Analysis of weather data. For the purpose of this analysis, on-site measurements of wetness duration and air temperature were assumed to approximate reality, and deviations of SkyBit simulations from these values were assumed to be errors. This was a reasonable assumption because all wetness sensors were calibrated during wetness events before deployment. Daily data sets were arbitrarily begun and ended at 12:00 noon. Differences between measured and SkyBit-simulated values of wetness duration and temperature were summarized for 24-h periods and averaged over the entire season. Differences between wetnessduration measurements and simulations were compared on days with and without rainfall to assess the accuracy of SkyBit simulations for rain and dew events. Analysis of variance was used to compare differences for days with and without rainfall. Differences between wetness measurements and simulations also were subdivided according to whether they occurred at the start, middle, or end of measured wet periods, between these periods, or during periods in which no wetness was measured.

TOM-CAST and Melcast simulations. We simulated the impact of SkyBit wetness-estimation errors on fungicide spray advisories issued by two disease-warning systems: TOM-CAST, devised by R. E. Pitblado for early blight (pathogen: Alternaria solani), Septoria leaf spot (Septoria lycopersici), and anthracnose fruit rot of tomatoes (Colletotrichum coccodes) (4); and Melcast, for Alternaria leaf blight of muskmelon (Alternaria cucumerina) (10). Both TOM-CAST and Melcast advise application of a protectant fungicide spray when the sum of daily disease-risk ratings,

Table 1. Distribution parameters for differences (h) between measured and SkyBit-simulated wetness duration

\begin{tabular}{lrcc}
\hline Location & $\boldsymbol{n}^{\mathbf{a}}$ & Mean $(\bar{x})^{\mathbf{b}}$ & SE $(\bar{x})^{\mathbf{c}}$ \\
\hline Acton, MA & 104 & 4.9 & 0.6 \\
Ames, IA & 99 & 3.2 & 0.6 \\
Decker, IN & 76 & 6.7 & 0.7 \\
Donaldson, NJ & 108 & 1.5 & 0.5 \\
Harrow, Ont. & 73 & 3.0 & 0.6 \\
Leamington, Ont. & 94 & 5.9 & 0.5 \\
Mondamin, IA & 69 & 2.7 & 0.3 \\
Muscatine, IA & 68 & 3.3 & 0.6 \\
Napoleon, OH & 118 & 3.4 & 0.5 \\
O'Hara, NJ & 107 & 1.8 & 0.5 \\
Oaktown, IN & 75 & 6.5 & 0.7 \\
O'Neall, IN & 90 & 3.8 & 0.6 \\
Ridgetown, Ont. & 86 & -0.1 & 0.5 \\
Scibilia, NJ & 106 & 0.9 & 0.5 \\
Snyder Farm, NJ & 129 & 2.1 & 0.4 \\
S. Deerfield, MA & 100 & 5.9 & 0.6 \\
Stratford, IA & 98 & 5.4 & 0.6 \\
SWPAC, IN & 80 & 3.4 & 0.6 \\
All locations & 1,680 & & \\
\hline
\end{tabular}

${ }^{a}$ Number of 24-h periods included in the analysis. Calendar dates of data sets varied by location; start dates ranged from 16 May to 16 June and end dates varied from 16 August to 30 September.

${ }^{\mathrm{b}}$ Arithmetic mean difference (measured-simulated).

c Standard error of mean.

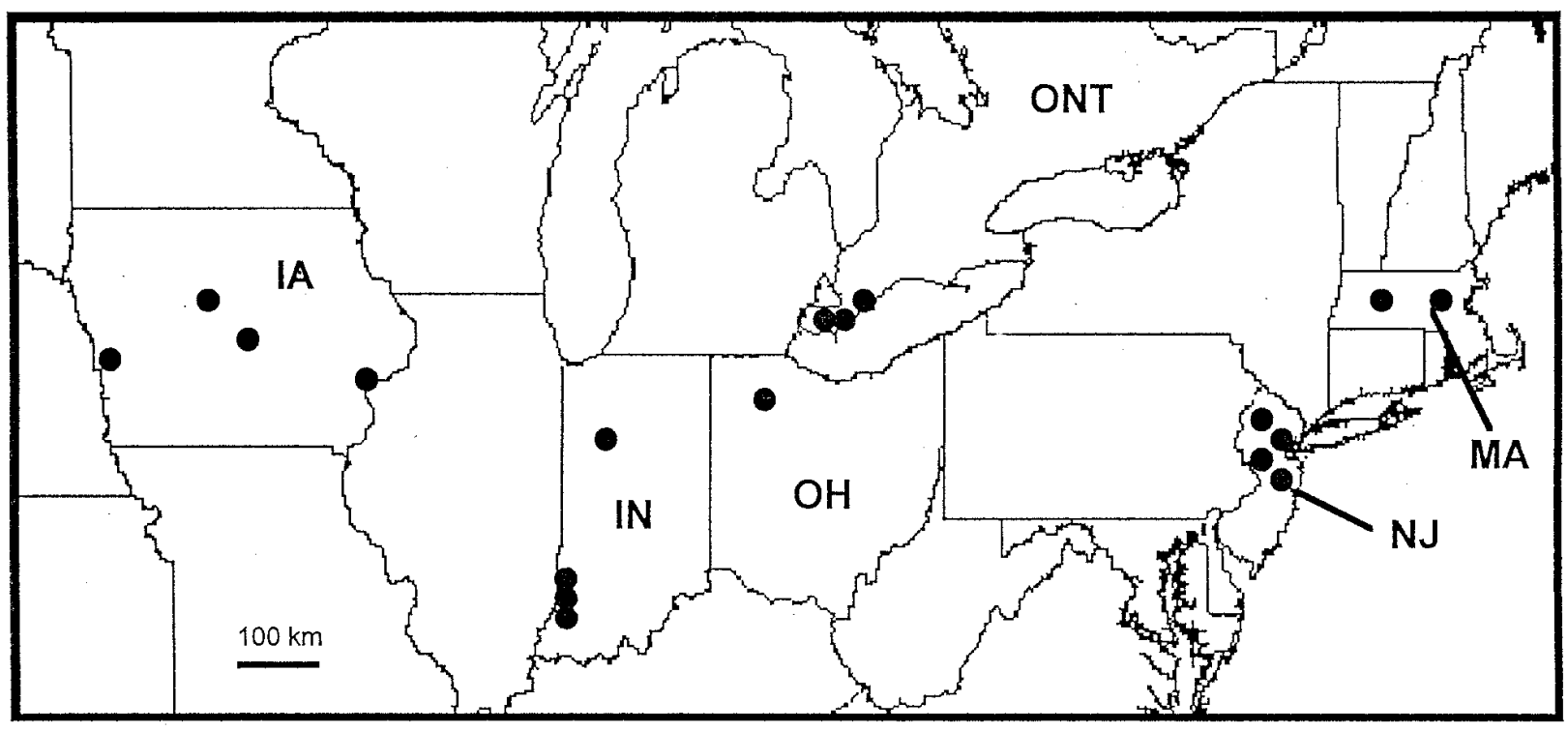

Fig. 1. Location of the field sites. 
termed "disease severity values" (DSV) for TOM-CAST and "environmental favorability indices" (EFI) for Melcast, reaches a threshold value.

To avoid variability in model response caused by inconsistent data record lengths at individual sites, we chose to simulate a 100-day growing season without reference to calendar date. The simulations used a threshold of 35 DSV for the first TOMCAST fungicide spray advisory of the season and 15 DSV for the second and subsequent sprays (4). The EFI threshold for Melcast was 20 throughout the simulation period (10). A computer program varied daily wetness-duration values randomly

Table 2. Mean differences $(x)$ between measured and SkyBit-simulated values of daily wetness duration (h) for rain days and nonrain days

\begin{tabular}{|c|c|c|c|c|c|c|}
\hline & & & & & \multicolumn{2}{|c|}{ Rain vs. nonrain } \\
\hline & \multicolumn{2}{|c|}{ Rain days } & \multicolumn{2}{|c|}{ Nonrain days } & \multirow[b]{2}{*}{$\boldsymbol{F}$} & \multirow{2}{*}{$\begin{array}{c}P>F \\
\text { Ho: } \bar{x}_{1}=\bar{x}_{2}\end{array}$} \\
\hline & $n^{\mathrm{a}}$ & $\bar{x}_{1}(\mathrm{SE})^{\mathrm{b}}$ & $n$ & $\bar{x}_{2}(\mathrm{SE})$ & & \\
\hline Harrow, Ont. & 21 & $-0.4(0.6)^{\mathrm{c}}$ & 51 & $4.4(0.7)$ & 18.44 & 0.0001 \\
\hline Leamington, Ont. & 34 & $3.2(1.0)$ & 60 & $7.5(0.5)$ & 16.75 & 0.0001 \\
\hline Ridgetown, Ont. & 35 & $3.3(0.8)$ & 51 & $6.3(0.6)$ & 8.60 & 0.0043 \\
\hline Muscatine, IA & 17 & $-0.7(1.3)^{\mathrm{c}}$ & 51 & $4.5(0.6)$ & 18.59 & 0.0001 \\
\hline Ames, IA & 36 & $2.1(1.1)^{\mathrm{c}}$ & 60 & $3.9(0.7)$ & 2.14 & 0.1471 \\
\hline Napoleon, $\mathrm{OH}$ & 24 & $0.2(1.2)^{\mathrm{c}}$ & 94 & $4.2(0.5)$ & 13.01 & 0.0005 \\
\hline Mean $^{\mathrm{d}}$ & & 1.7 & & 5.0 & & \\
\hline
\end{tabular}

a Number of 24-h periods included in the analysis.

b Arithmetic mean difference (measured-simulated) and standard error of the mean.

c $X$ is not significantly different from zero $\left(P>t>0.05, \mathrm{H}_{\mathrm{o}}: X=0\right)$.

${ }^{\mathrm{d}}$ Unweighted mean.

Table 3. Percentage of hours in which measured wetness status (wet or dry) was misidentified by SkyBit

\begin{tabular}{lccccc}
\hline Location & $\begin{array}{c}\text { Total h with } \\
\text { measured } \\
\text { wetness }\end{array}$ & $\begin{array}{c}\text { Wet h } \\
\text { identified } \\
\text { as dry (\%) }\end{array}$ & $\begin{array}{c}\text { Total h without } \\
\text { measured } \\
\text { wetness }\end{array}$ & $\begin{array}{c}\text { Dry h } \\
\text { identified as } \\
\text { wet (\%) }\end{array}$ & $\begin{array}{c}\text { Total h } \\
\text { identified } \\
\text { correctly (\%) }\end{array}$ \\
\hline Acton, MA & 1,259 & 59.8 & 1,236 & 9.1 & 65.3 \\
Ames, IA & 1,085 & 89.0 & 1,259 & 13.0 & 65.7 \\
Donaldson, NJ & 980 & 56.4 & 1,612 & 9.9 & 72.5 \\
Harrow, Ont. & 670 & 50.7 & 1,005 & 11.9 & 72.5 \\
Leamington, Ont. & 1,110 & 61.9 & 1,082 & 10.5 & 63.5 \\
Mondamin, IA & 766 & 61.1 & 1,524 & 4.5 & 76.6 \\
Muscatine, IA & 807 & 54.3 & 772 & 13.5 & 65.7 \\
O'Hara, NJ & 929 & 55.0 & 1,615 & 8.1 & 74.8 \\
Ridgetown, Ont. & 731 & 66.6 & 1,243 & 5.2 & 72.0 \\
Scibilia, NJ & 675 & 41.2 & 1,710 & 11.8 & 79.9 \\
Snyder Farm, NJ & 882 & 38.9 & 2,213 & 10.4 & 81.5 \\
S. Deerfield, MA & 1,118 & 51.2 & 1,259 & 16.3 & 67.3 \\
All 12 locations & 11,012 & 55.1 & 16,530 & 10.1 & 71.9 \\
\hline
\end{tabular}

about three means so that the standard deviation of the simulated values was $5.7 \mathrm{~h}$, equivalent to that of measured wetness duration for all stations and dates (data not shown). The mean values of the three daily wetness duration distributions that were input to TOM-CAST and Melcast were based on: (i) mean duration of measured wetness for all stations and dates (10.0 $\mathrm{h} /$ day); (ii) mean measured wetness duration less the mean difference between measurements and SkyBit-simulated wetness duration for all stations and dates $(10.0-3.4=$ $6.6 \mathrm{~h} /$ day); or (iii) mean measured wetness duration less the largest mean difference between measurements and SkyBit-simulated wetness duration at any site $(10.0-6.7$ $=3.3 \mathrm{~h}$ /day). Simulated mean air temperatures during wet periods were generated as random values from a distribution with a mean of $19.0^{\circ} \mathrm{C}$ and standard deviation of 6.0, which approximated the observed distribution of temperature measurements for all sites. On a given day, however, the simulation program assigned the same air temperature for each of the three simulated values of wetness duration.

\section{RESULTS}

The number of 24-h periods included in data records for individual locations ranged from 68 to 129 , for a total of 1,680 observation days. Records of hourly temperature measurements were available for 13 stations, and hourly rainfall measurements were available for six stations.

Mean differences between on-site measurements and SkyBit simulations varied widely among sites, but SkyBit underestimated wetness duration at most sites (Table 1). The average underestimate was $3.4 \mathrm{~h} /$ day. Large standard deviations indicated considerable variability in the accuracy of the SkyBit wetness estimates at many sites. SkyBit averages for mean, maximum, and minimum daily temperatures

Table 4. Wetness hours identified incorrectly by SkyBit and timing of errors relative to on-site measurements of wetness duration

\begin{tabular}{|c|c|c|c|c|c|c|c|c|c|c|c|}
\hline \multirow[b]{2}{*}{ Location } & \multirow[b]{2}{*}{$\begin{array}{c}\text { Total h } \\
\text { wet }^{\mathrm{a}}\end{array}$} & \multirow[b]{2}{*}{$\begin{array}{c}\text { Wet } \mathbf{h} \\
\text { missed }^{\mathrm{b}}\end{array}$} & \multicolumn{4}{|c|}{ Wet hours misidentified as dry (\%) } & \multirow[b]{2}{*}{$\begin{array}{c}\text { Wet h } \\
\text { added by } \\
\text { SkyBit }^{d}\end{array}$} & \multicolumn{4}{|c|}{ Dry hours misidentified as wet $(\%)$} \\
\hline & & & $\begin{array}{l}\text { Start of } \\
\text { wet } \\
\text { period }\end{array}$ & $\begin{array}{c}\text { Mid- } \\
\text { period }^{c}\end{array}$ & $\begin{array}{c}\text { End of } \\
\text { wet } \\
\text { period }\end{array}$ & $\begin{array}{c}\text { Entire wet } \\
\text { period } \\
\text { missed }\end{array}$ & & $\begin{array}{l}\text { Start of } \\
\text { wet } \\
\text { period }\end{array}$ & $\begin{array}{c}\text { Between } \\
\text { wet } \\
\text { periods }^{\mathrm{e}}\end{array}$ & $\begin{array}{l}\text { End of } \\
\text { wet } \\
\text { period }\end{array}$ & $\begin{array}{c}\text { Entire } \\
\text { period in } \\
\text { error }\end{array}$ \\
\hline Acton, MA & 1,259 & 753 & 24.8 & 3.2 & 10.9 & 61.0 & 113 & 14.2 & 39.8 & 46.0 & 0 \\
\hline Ames, IA & 1,085 & 640 & 33.1 & 7.2 & 7.7 & 52.0 & 164 & 8.5 & 2.4 & 63.4 & 25.6 \\
\hline S. Deerfield, MA & 1,118 & 572 & 51.6 & 4.0 & 4.7 & 39.7 & 205 & 11.2 & 27.3 & 61.5 & 0 \\
\hline Donaldson, NJ & 980 & 553 & 27.7 & 1.8 & 6.3 & 64.2 & 160 & 14.4 & 16.3 & 48.8 & 20.6 \\
\hline Harrow, Ont. & 670 & 340 & 22.4 & 7.9 & 8.2 & 61.5 & 120 & 35.8 & 10.8 & 43.3 & 10 \\
\hline Leamington, Ont. & 1,110 & 687 & 15.1 & 6.6 & 13.5 & 64.8 & 114 & 20.2 & 45.6 & 26.3 & 7.9 \\
\hline Mondamin, IA & 766 & 468 & 29.9 & 2.4 & 3.0 & 64.7 & 69 & 26.1 & 2.9 & 60.9 & 10.1 \\
\hline Muscatine, IA & 807 & 438 & 48.4 & 5.5 & 4.1 & 42.0 & 104 & 0 & 12.5 & 7.7 & 79.8 \\
\hline O'Hara, NJ & 929 & 511 & 25.4 & 2.0 & 6.7 & 65.9 & 131 & 25.2 & 18.3 & 38.9 & 17.6 \\
\hline Ridgetown, Ont. & 731 & 487 & 15.2 & 4.9 & 2.7 & 77.2 & 65 & 30.8 & 20.0 & 30.8 & 18.5 \\
\hline Scibilia, NJ & 675 & 278 & 17.6 & 6.1 & 9.4 & 66.9 & 201 & 16.4 & 20.9 & 47.3 & 15.4 \\
\hline Snyder Farm, NJ & 882 & 343 & 30.0 & 7.6 & 10.8 & 51.6 & 230 & 27.0 & 16.5 & 37.0 & 19.6 \\
\hline All 12 locations & 11,012 & 6,070 & 28.4 & 4.9 & 7.3 & 59.3 & 1,676 & 18.4 & 19.6 & 44.3 & 17.7 \\
\hline
\end{tabular}

a Measured by electronic wetness sensors.

${ }^{\mathrm{b}}$ On-site sensors measured wetness, but SkyBit simulated dry conditions during the hour.

c SkyBit interpreted a single wet period as two discontinuous periods.

d On-site sensors did not detect wetness, but SkyBit simulated wetness was present.

e SkyBit interpreted discontinuous wet periods as one continuous wetness event. 
varied from on-site measurements by less than $0.7^{\circ} \mathrm{C}$ (data not shown), so temperature differences between SkyBit and on-site measurements were not analyzed further.

At five of the six stations that recorded rainfall, SkyBit underestimates of wetness duration were significantly $(P<0.01)$ larger for days without rainfall than for days on which rainfall was measured (Table 2). The average SkyBit underesti-

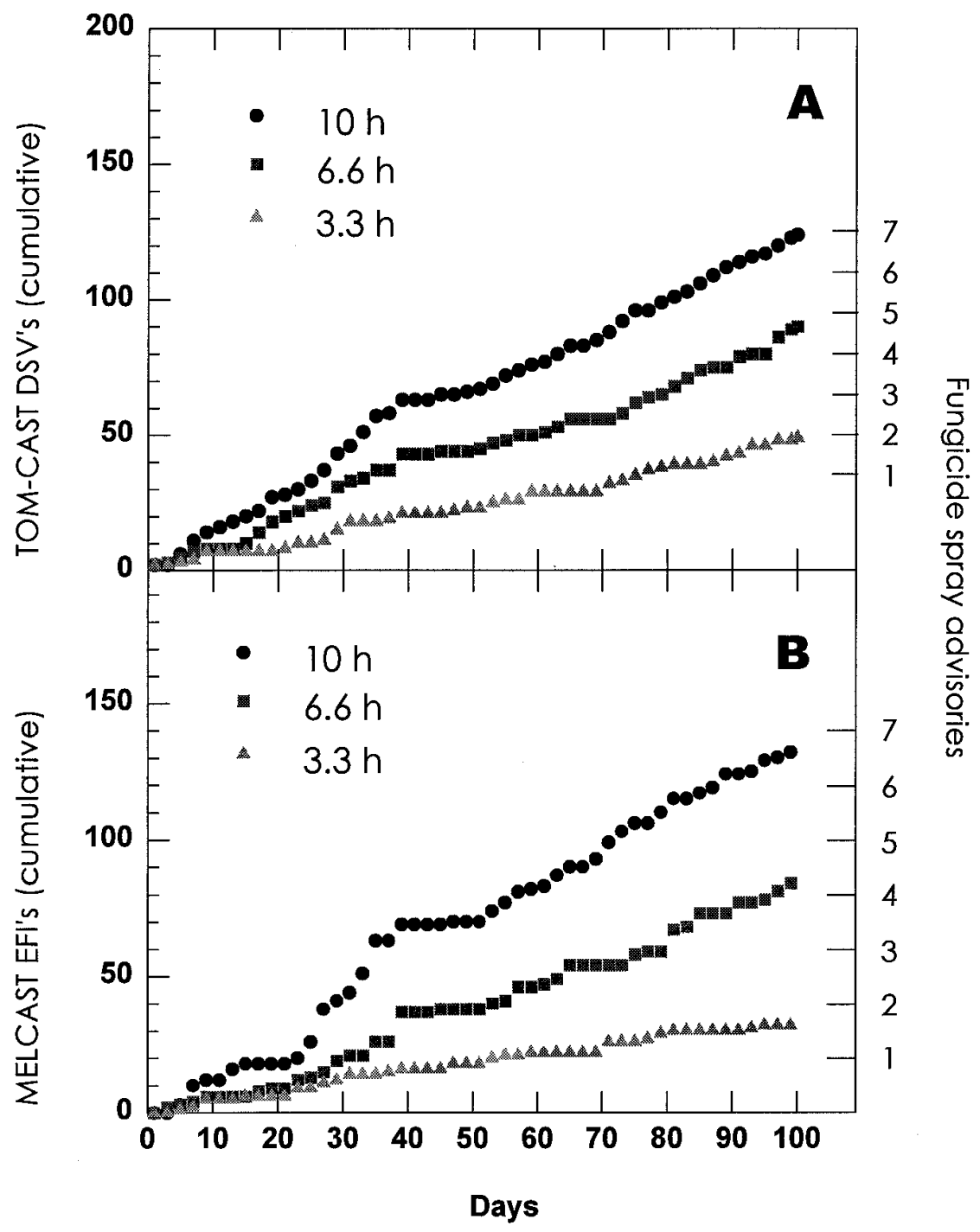

Fig. 2. Accumulation of TOM-CAST disease severity values (DSV) (A) and Melcast environmental favorability indices (EFI) (B) over a simulated 100-day growing season. Mean daily wetness durations were $10.0 \mathrm{~h}$ (mean of measurements for all sites and dates), $6.6 \mathrm{~h}$ (adjusted for mean SkyBit underestimate of wetness duration for all stations and dates), or $3.4 \mathrm{~h}$ (adjusted for largest mean SkyBit underestimate of wetness duration for any site). Fungicide spray advisories are indicated in ascending order, beginning with 1 , the first spray advisory of the season. mate of wetness duration was $5.0 \mathrm{~h}$ on nonrain days and $1.7 \mathrm{~h}$ on rain days, a nearly threefold difference.

At the 12 stations for which hourly wetness measurement records were available, SkyBit misidentified $55.1 \%$ of measured wet hours as dry (Table 3 ). The mean error rate for hours measured as dry, but misidentified by SkyBit as wet, was much lower $(10.1 \%)$. A majority $(59.3 \%)$ of the hours that SkyBit misidentified as dry occurred during wetness events that were missed entirely by SkyBit (Table 4). An additional large component (28.4\%) of wet hours was missed at the beginning of wetness periods, whereas fewer hours were missed at the end of a wetness period $(7.3 \%)$ or when SkyBit simulated a dry period during a continuous period of measured wetness $(4.7 \%)$.

TOM-CAST and Melcast accumulated DSV and EFI, respectively, progressively more slowly when mean daily wetness duration was reduced by $3.4 \mathrm{~h} /$ day (the overall mean difference between SkyBit and measured wetness duration) or 6.7 $\mathrm{h}$ /day (the largest mean difference observed for any station) (Fig. 2). Simulated wetness values, adjusted to reflect the overall mean underestimate and largest observed mean underestimate, resulted in fewer fungicide spray advisories and time lags of 8 to 49 days in issuing spray advisories compared with the $10 \mathrm{~h} /$ day standard (Table 5). When simulated mean wetness duration values averaged $6.6 \mathrm{~h} /$ day instead of $10 \mathrm{~h} /$ day, TOM-CAST spray advisories were 8,24 , and 34 days late and Melcast advisories were 8,24 , and 43 days late for the first, second, and third sprays of the season, respectively.

\section{DISCUSSION}

SkyBit simulations of daily wetness duration differed substantially from on-site measurements. In general, SkyBit underestimated the duration of wet periods. This trend prevailed over a broad geographic region despite different sensor designs, coatings, deployment angles, and microenvironments. Even at four New Jersey stations where the SkyBit underestimates were relatively small $(<2 \mathrm{~h} /$ day $)$, variability in the size of estimation errors was

Table 5. Number of fungicide sprays recommended by TOM-CAST and Melcast disease-warning systems for mean daily wet periods of $10.0 \mathrm{~h}^{\mathrm{a}}, 6.6 \mathrm{~h}^{\mathrm{b}}$, and $3.3 \mathrm{~h}^{\mathrm{c}}$, and time lags of fungicide spray advisories for the first three sprays of the season in the $6.6 \mathrm{~h} / \mathrm{day}$ and $3.3 \mathrm{~h} /$ day wetness simulations compared with $10.0 \mathrm{~h} /$ day wetness duration

\begin{tabular}{|c|c|c|c|c|c|c|c|c|c|}
\hline \multirow{3}{*}{$\begin{array}{l}\text { Disease-warning } \\
\text { system }\end{array}$} & \multirow{2}{*}{\multicolumn{3}{|c|}{ Fungicide sprays per season }} & \multicolumn{6}{|c|}{ Time lagd } \\
\hline & & & & \multicolumn{2}{|c|}{ First spray } & \multicolumn{2}{|c|}{ Second spray } & \multicolumn{2}{|c|}{ Third spray } \\
\hline & $10.0 \mathrm{~h}$ & $6.6 \mathrm{~h}$ & $3.3 \mathrm{~h}$ & $6.6 \mathrm{~h}$ & $3.3 \mathrm{~h}$ & $6.6 \mathrm{~h}$ & $3.3 \mathrm{~h}$ & $6.6 \mathrm{~h}$ & $3.3 \mathrm{~h}$ \\
\hline TOM-CAST & 6 & 4 & 1 & 8 & 49 & 24 & $\ldots$ & 34 & $\ldots$ \\
\hline Melcast & 6 & 4 & 1 & 8 & 29 & 22 & $\ldots$ & 43 & $\ldots$ \\
\hline
\end{tabular}

${ }^{a}$ Mean of daily wetness duration measured at all sites and dates.

b $10.0 \mathrm{~h} /$ day $-3.4 \mathrm{~h} /$ day. $3 / 4 \mathrm{~h} /$ day = mean SkyBit underestimate of wetness duration for all stations and dates.

${ }^{c} 10.0 \mathrm{~h} /$ day $-6.7 \mathrm{~h} /$ day. $6.7 \mathrm{~h} /$ day = largest mean SkyBit underestimate of wetness duration for any station (Decker, IN).

$\mathrm{d}$ Assuming a mean air temperature of $19.0^{\circ} \mathrm{C}$, with a standard deviation of $6.0^{\circ} \mathrm{C}$, during wetness periods, an initial-spray advisory threshold of 35 disease severity values (DSV) and a threshold of 15 DSV for subsequent spray advisories (4). 
quite large. Errors in estimation of air temperature were relatively small. Truxall (17), comparing on-site measurements and SkyBit-simulated forecast data for 2 months at a single site (Rock Springs, PA), found that SkyBit forecasts were fairly accurate predictors of air temperature but underpredicted measured relative humidity.

SkyBit underestimates of wet-period duration were much larger for dew than for rain periods. Possible sources of inaccuracy include the simulated inputs to SkyBit's wetness-estimation algorithm (e.g., wind speed, relative humidity, air temperature) and the algorithm itself. The present study, however, did not quantify the relative contributions of these sources. In other work, empirical (5) or energybalance (11) models, based on measurements of standard meteorological parameters, estimated the timing (11) or duration (5) of dew periods with considerably more accuracy than did SkyBit in the present study. The vast majority $(87.7 \%)$ of hours SkyBit misclassified as dry occurred either when entire wet periods were missed or when the onset of a wet period was detected late. Therefore, revision of SkyBit wetness-simulation models could focus on reducing error rates during these periods.

In our simulations, TOM-CAST and Melcast recommended fewer and later fungicide sprays when means of measured wetness duration were reduced by mean SkyBit errors. These changes potentially could compromise disease control efficacy. Our simulations, however, did not attempt to simulate the impact, if any, of delayed fungicide sprays on disease development. Field trials at many locations over several growing seasons are needed to determine the impact of SkyBit wetness-simulation errors on crop disease control. Based on a 2-month, single-site field trial using the Penn State Apple Orchard Consultant disease-warning system for apple scab (pathogen: Venturia inaequalis) (18), Russo et al. (14) concluded that timing of fungicidespray recommendations based on SkyBitsimulated weather inputs for air temperature, relative humidity, and precipitation varied little from recommendations derived from on-site measurements, but did not document impacts on disease control. In operational use, factors that were ignored in our simulation will affect the degree to which SkyBit wetness-estimation errors influence the performance of TOM-CAST or Melcast. Examples of these real-world factors include decision rules that supplement the basic disease-warning algorithm, such as those based on crop development stage (e.g., Melcast specifies applying the first fungicide spray when vines in adjacent rows converge [10]) or calendar date (e.g., TOM-CAST specifies application of a fungicide spray on 11 July if none was applied earlier [4]). For other diseasewarning systems, the impact of SkyBit errors on system performance will also depend on each system's characteristic sensitivity to particular input parameters, such as wetness duration, air temperature, relative humidity, and precipitation.

Our study is in several ways a stringent test of SkyBit. Most growers who are potential users of disease-warning systems do not measure hourly wetness or air temperature on their farms. If they use such systems, growers often depend on wetness and temperature measurements made many miles away under the assumption-typically untested-that weather conditions on their farm closely mimic those at the measurement site (4). A more realistic test of SkyBit's accuracy, therefore, would compare its errors with errors incurred in using wetness and temperature measurements taken at various distances (e.g., 10, 20 , or $40 \mathrm{~km}$ ) from a production field. Moreover, on-site measurements of environmental parameters, especially wetness duration, can vary greatly within a crop canopy. Measurements made adjacent to, or even within, a crop canopy are at best only approximations of wetness duration elsewhere in the canopy or the field. For some crops and disease-warning systems, weather data, whether measured or estimated, may need to be calibrated to account for characteristics of the crop canopy and microtopography $(1,13,17)$. Furthermore, wetness-duration measurements are subject to errors whose magnitude can vary with sensor design $(6,15)$, surface coating $(3,6)$, orientation (3), and calibration method $(5,12,15)$. All of these potential error sources were present our study.

We have demonstrated that errors in SkyBit-simulated leaf wetness can substantially alter the behavior of diseasewarning systems, and that the magnitude of the impact depends on the particular system. These errors need to be reduced before simulations can be a reliable source of wetness-duration estimates for diseasewarning systems. The approach used here could be applied to validate other wetnessestimation models in the future.

Documentation of the magnitude of SkyBit's wetness-estimation errors should not be interpreted as a rejection of this approach. Electronic weather services are a new and emerging technology that shows great promise for application to disease management. Our work illustrates that university and agribusiness researchers must work together with the designers of this new technology to ensure that their products meet the needs of decision makers in the field. Recently (October 1996), SkyBit introduced new versions of its E-Weather models that are designed to address shortcomings in the simulation and forecasting of environmental wetness periods (J. Russo, SkyBit, personal communication).

\section{ACKNOWLEDGMENTS}

We thank G. P. Munkvold, X. B. Yang, and J. M. Russo for critical review of the manuscript.
Journal paper No. J-17166 of the Iowa Agriculture and Home Economics Experiment Station, Ames, Project No. 3206. Supported by Hatch Act and State of Iowa funds.

\section{LITERATURE CITED}

1. Campbell, C. L., and Madden, L. V. 1990. Introduction to Plant Disease Epidemiology. John Wiley \& Sons, New York.

2. Funt, R. C., Ellis, M. A., and Madden, L. V. 1990. Economic analysis of protectant and disease-forecast-based fungicide spray programs for control of apple scab and grape black rot in Ohio. Plant Dis. 74:638-642.

3. Gillespie, T. J., and Kidd, G. E. 1978. Sensing duration of leaf moisture retention using electrical impedance grids. Can. J. Plant Sci. 58:179-187.

4. Gleason, M. L., MacNab, A. A., Pitblado, R. E., Ricker, M. D., East, D. A., and Latin, R. X. 1995. Disease-warning systems for processing tomatoes in eastern North America: Are we there yet? Plant Dis. 79:113-121.

5. Gleason, M. L., Taylor, S. E., Loughin, T. M., and Koehler, K. J. 1994. Development and validation of an empirical model to estimate the duration of dew periods. Plant Dis. 78:1011-1016.

6. Huband, N. D. S., and Butler, D. R. 1984. A comparison of wetness sensors for use with computer or microprocessor systems designed for disease forecasting. Proc. Br. Crop Prot. Conf. 2:633-638.

7. Huber, L., and Gillespie, T. J. 1992. Modeling leaf wetness in relation to plant disease epidemiology. Annu. Rev. Phytopathol. 30:553577.

8. Kaplan, M. L., Zack, J. W., Wong, V. C., and Tucillo, J. J. 1982. Initial results from an atmospheric simulation system and comparisons with an AVE-SESAME I data set. Mon. Weather Rev. 110:1564-1590.

9. Kelley, J. G. W., Russo, J. M., Eyton, J. R., and Carlson, T. N. 1988. Mesoscale forecasts generated from operational numerical weather-prediction model output. Bull. Am. Meteorol. Soc. 69:7-15.

10. Latin, R., and Evans, K. J. 1996. Development and delivery of a forecaster for Alternaria leaf blight of muskmelon. (Abstr.) Phytopathology 86:S106.

11. Pedro, M. J., and Gillespie, T. J. 1982. Estimating dew duration. I. Utilizing meteorological data. Agric. Meteorol. 25:297-310.

12. Potratz, K. J., Gleason, M. L., Hockmuth, M L., Parker, S. K., and Pearston, G. A. 1994. Testing the accuracy and precision of wetness sensors in a tomato field and on turfgrass. J. Iowa Acad. Sci. 101:56-60.

13. Royer, M. H., Russo, J. M., and Kelley, J. G. W. 1989. Plant disease prediction using a mesoscale weather forecasting technique. Plant Dis. 73:618-624.

14. Russo, J. M., Travis, J. W., and Truxall, D. L. 1996. Simulated mesoscale weather data as input into an apple expert system. Pages 334335 in: Proc. Conf. Agric. For. Meteor., 22nd. Amer. Meteor. Soc., Boston, MA.

15. Sutton, J. C., Gillespie, T. J., and Hildebrand, T. J. 1984. Monitoring weather factors in relation to plant disease. Plant Dis. 68:78-84.

16. Thompson, N. 1981. The duration of leaf wetness. Meteorol. Mag. 110:1-12.

17. Truxall, D. L. 1995. An environmentally driven model for grape black rot scouting and the impact of environmental data differences on disease control decision-making. Ph.D. thesis. Pennsylvania State University, University Park.

18. Truxall, D. L., and Travis, J. W. 1994. Analysis of the accuracy of predicted weather data on the impact of apple disease management. (Abstr.) Phytopathology 84:1125. 